\title{
2000 国家大地坐标系转换常见问题分析
}

钱亮

湖北创易行工程项目管理有限公司

DOI:10.32629/gmsm.v2i2.127

[摘 要] 2008 年 7 月 1 日,我国正式启用 2000 国家大地坐标系。本文针对 2000 国家大地坐标系的概况、转换方法及常见转 换问题进行了分析,提出切实可行的计算处理方案,为测绘工作提供科学的指导。

[关键词] 2000 国家大地坐标系; 转换; 问题; 分析

引言

国家大坐标系统通过大地坐标的框架来实现,也是国家 大地基准中平面基准为用户提供服务的重要实际途径。而各 地方完成现行国家大地坐标系, 建立地方独立坐标系, 并向 2000 国家大地坐标系转换, 已成为目前其启用和推广的重要 工作之一。

\section{0 国家大地坐标系概况}

1.12000 国家大地坐标系概述

坐标系原点、尺度、三个坐标轴的指向、地球椭球等是 构成国家大地坐标系四个基本参数。2000 国家大地坐标系 将海洋及整个地球大气的质量中心作为原点, 其 $Z$ 轴的指向 是从原点到历元 2000.0 的地球参考极, 历元 2000.0 的指向 通过 1984.0 的初始指向推算, 此指向由国际时间局给定, 相 对的地壳全球旋转时不产生残余由定向的时间演化来保证。 $\mathrm{X}$ 轴由原点指向格林尼治参考子午线与地球赤道面的交点, 轴与 $Z$ 轴、 $X$ 轴构成右手正交坐标系, 利用较为广义的理论 意义下的尺度。

\section{2 建立地方坐标系的概况}

为达到我国经济发展建设的需求, 地方独立坐标系开始 在较少部分区域或行业内建立, 区域坐标系的建立在当时技 术发展情况下主要依据传统大地测量手段。在城市或工程建 设区域, 地方独立坐标系在进行布设测量控制网时, 不仅要 满足 $1: 1000$ 等大比例尺测图需求, 还要为一般工程提供放 样需求。在提供工程施工放样时, 在控制网的规划中反算的 长度与实测的长度差应符合规范要求, 其与国家坐标系的坐 标成果相比, 能满足这样的基本需求, 而国家坐标系无法实 现。这是因为其投影带有明确的划分, 如 6 度带或 3 度带。 另外, 国家坐标系根据参考椭球面进行高程归化面的设计, 并根据每个地区相应的地面位置与参考粗球面的距离, 这两 个因素将导致高斯投影变形及高程归化改正的产生, 这两项 改正将会导致长度与实测长度不相等。地方独立坐标系在建 立时应遵循一定原则, 在城市范围内保证长度的变形能够满 足每千米小于 $2.5 \mathrm{~cm}$ 的长度变形要求。

\section{0 国家大地坐标系的特点}

2.1 椭球定位方式不同

2000 国家大地坐标系为地心坐标系, 它的定义将粗球中 心与地球质心重合, 并且椭球定位与全球大地水准面最为密 和。2000 国家大地坐标系为实现局部球面形状的研究, 在遵 循粗球各改正数量最小的原则下, 经地面测量数据归算入内, 选择与本区域内局部大地水准面最密合的椭球建立坐标系。

\section{2 实现技术不同}

参心坐标的建立依据大地测量的传统手段, 就是测量不 同标志点之间的距离、方向, 采用平差的方法计算不同标志 点与原点的位置, 根据此来确定不同标志点的坐标系。2000 国家大地坐标系主要运用大地测量观测技术进行框架建立, 以获取各个测站在框架下的地心坐标。

\section{3 维数与原点不同}

现行的参心坐标系为二维坐标系, 而 2000 国家大地坐 标系采用的是三维坐标系。参心坐标系其原点与地球质量中 心存在很大程度上的偏差, 2000 国家大地坐标系的原点就位 于地球质量中心。

\section{0 国家大地坐标系转换方法}

\section{1 坐标归算}

坐标归算适用于 CGCS2000 的省级 GNSS 基准站和卫星大 地控制点坐标向 CGCS2000 的坐标转换。即对拟转换点采用 与周边稳定的 IGS 站及国家 GNSS 连续运行基准站进行联测 的方法。即先对拟转换点利用其周边稳定 IGS 站, 将其与国 家级 GNSS 连续运行基准站实现联合测量的方法, 以获取不 同站点 ITRF 框架、观测历元下的位置, 经过历元归算、框架 转换等步骤进行坐标归算。坐标归算转换方法的实现必须对 网中不同站的速度场获知。

\section{2 参数转换}

参数转换适用于没有联测已知点的卫星大地控制点和 三维点坐标向 CGCS2000 的坐标转换。即按照转换区域选取 适当的转换模型 (布尔莎模型、三维七参数模型、三维四参 数模型、二维四参数模型、多项式拟合模型等), 选择重合点, 
经粗差剔除后计算转换参数, 进行坐标转换。

\section{0 国家大地坐标系转换常见问题分析}

4.1 坐标归算

运用坐标归算方法进行 2000 国家大地坐标系转换的关 键步骤是：国家级 GNSS 基准站、国家 GNSS 大地控制点等基准 控制点的选取、高精度数据处理、框架转换等。在利用坐标归 算进行 2000 国家大地坐标系转换时常常出现的问题, 一个是关 于基准控制点的选取, 另一个是板块运动改正方面。

4. 1.1 CGCS2000 起算点坐标。起算点坐标不属于国家 测绘行政主管部门权威发布的 CGCS2000 坐标。一些省份采 用的 CGCS2000 起算点坐标为非国家测绘行政主管部门权威 发布的, 通过其建立的基础控制网, 或不能量值溯源到国家 测绘行政主管部门权威数据。

4.1.2 起算点精度等级不符合等级控制点要求。一些省 份基础控制网在建立时没有与 IGS 站或国家级 GNSS 基准站 实现联测, 控制点联测仅仅保持与本省或周围省市的 2000 国家 GPS 大地控制网进行, 通过约束平差获得 CGCS2000 坐 标。其在 GPS 控制点的 C、D 级转换时, 能够保证成果与本省 地区其他成果基本相同。省级 GNSS 基准站是省级大地基准 的重要支撑和骨干, 通过以上转换方法符合当时省级发展条 件下和过渡期的 CGCS2000 坐标推广和使用, 但现阶段, 对于 省级三维、动态地心坐标系统的维持是不利的, 在大地控制 网点三维表坐标的起算精度上是不能保证的, 不符合等级控 制点的要求, 且与当前的形式和全国方面不能保持统一。

4.2 参数转换

运用参数转换方法进行 2000 国家大地坐标系转换的关 键步骤是转换分区、转换模型的选取、转换参数计算等。目 前, 在参数转换方法中常出现的问题有：转换分区、重合点 覆盖范围、重合点的剔除外部点检核等 4 个方面:

4.2.1 1954 北京坐标系的坐标是通过逐级控制分区平 差的方法实现推算过程的, 这其中存在一定显著的平差变形, 有的个别地区在锁网接合部点或转换分区还产生了成果上 的一致或产生了裂缝。因此, 在这样的地区, 不适合采用一个 转换分区和一套转换参数, 以避免较大误差出现。

4.2.2 参数转换中重合点的选取, 应以等级高、精度高 为基本原则, 并且保证局部变形小、分布均匀且重合点能覆 盖整个转换区域。如果出现重合点不能覆盖整个转换区域, 此时只能通过外推得到覆盖区域的转换参数, 但这时转换精 度会因外推距离放大而发生急剧损失, 导致本省的转换成果
与其他周边省市的成果形成不相符的的情况。

4. 2.3 粗差点剔除不严格, 粗差点剔除时未按照大于 2 倍点位中误差进行, 极易出现转换参数局部的变形。粗差点 剔除应将引起重合点分布不均匀的点包含在内, 比如应在最 大的范围内避免模型狭长三角形的出现, 但这种点可在外部 检核点中使用。

4.2. 4 外部检核点选取没有参与转换参数的重合点, 其 点数应多于 6 个且分布均匀。当外部检核点出现不足时, 可 通过野外实测检核, 特别要注意对转换区域边缘的检核。

\section{0 国家大地坐标系转换建议与措施}

\section{1 大地控制点类成果}

在平差计算过程中, 起算控制点 CGCS2000 成果应充分 利用通过向国家申领的 2000 国家 GPS 大地控制网成果大地 点成果, 还应将更高精度的 2000 国家 GPS 大地控制网 GNSS 连续运行基准站坐标更加充分利用起来。

通过省与省质检重合点数据的交换及参数转换模型的 建立, 尽量实现重合点覆盖全部转换区域, 对不能进行覆盖 的转换区域或参数可进行平滑外推, 同时要加强外部检核工 作及周边省的接边工作。

\section{2 基础地理信息数据成果}

现有的成果导致转换工作量大, 且各省可将现有基础地 理信息成果作为过渡性成果, 目前, 随着测绘工作的持续开 展, 新的基础地理信息数据成果较适宜通过 CGCS2000 生产, 并通过各省对现有成果转换, 以满足实际应用的需求、参数 转换过程时应注意确保数据的统一、完整以及唯一性。确保 转换到位、接边到位。

\section{6 结语}

综上所述, 2000 国家大地坐标系测绘成果数据转换, 可 根据收集的地方地方坐标系具体数据及情况, 通过多个公共 控制点坐标的获取, 进行相关转换参数。通过专业软件可实 现测绘成果数据的转换, 并达到一定范围内的精度要求, 满 足实际应用需要。

\section{[参考文献]}

[1]张训虎.现有成果转换为 2000 国家大地坐标系成果 检查方法探讨 [J].工程勘察,2015,43(2):85-89.

[2]宁津生,王华,程鹏飞,等.2000 国家大地坐标系框架体系建 设及其进展[J].武汉大学学报(信息科学版),2015,40(5):569-573.

[3]王百胜.传统参心坐标系与国家 2000 大地坐标系转 换问题研究[J].中国高新科技,2019,(02):22-24. 